\title{
LA HETEROGENEIDAD ENUNCIATIVA: Algunas manifestaciones de la heterogeneidad mostrada
}

\author{
Covadonga Pendones De Pedro \\ (Universidad de Madrid)
}

\begin{abstract}
RESUMEN
The object of the present article is to analyse in the most systematic form the steps that the enunciator leaves impressed in his speach by certain enunciatives phenomenoms, as per formal variations of the code, grammatical irregularities, interrupted speeches and use of typographical marks. The relevance in such phenomenoms is it's capacity to introduce other enuntiators voices through the word of the speaker, polyphonics acts which give place to interdiscoursives strategies which breaks or alters the image of a lineal speech.
\end{abstract}

\section{INTRODUCCION}

I.1. En un artículo publicado en $1984^{1}$, Jacqueline Authier-Revuz introdujo el concepto de heterogeneidad enunciativa para dar cuenta de diversos fenómenos discursivos formados por la capacidad interdiscursiva del discurso. Authier distingue entre dos tipos de heterogeneidad: constitutiva («constitutive») y mostrada («montrée»). La heterogeneidad constitutiva (HC) no se encuentra marcada en la superficie. Sin embargo, es posible descubrir que el discurso es un producto del interdiscurso (op.cit:99), gracias al análisis bahktiniano sobre el dialogismo, apoyado, asimismo, en los trabajos de Freud y Lacan sobre la relación del sujeto con su discurso:

\footnotetext{
1 «Hétérogénéite(s) énonciative(s)». Langages, 73.
} 
«(..) elle (AD) postule un fonctionnement réglé qui depuis d'ailleurs de l'interdiscours rend compte de la production du discours, machineire structurale ignorée du sujet qui, dans l'illusion, se croit source de son discours là où il n'en est le support, l'effect». (op.cit:100)

La $\mathbf{H C}$ pone en relación un discurso determinado con todos los discursos anteriores generados, a su vez, sobre la architextualidad (Genette,1979) de otros discursos también anteriores. En otras palabras, la interdiscursividad constitutiva se motiva en el trabajo de un discurso sobre otros discursos. El encuentro de ambos discursos puede ser interpretado como un proceso de traducción generalizado y ligado a la interincomprensión (Maingueneau, 1986:87). Se sobreentiende que se trata de una traducción de una formación discursiva a otra ${ }^{2}$. De ahí surge, precisamente, la relación polémica (op.cit:91), ya que una de las formaciones discursivas no acepta las unidades de sentido construidas por la otra formación, pues es a través de tal rechazo que puede definir su identidad.

Mientras la $\mathrm{HC}$ corresponde a los procesos reales de constitución de un discurso, la heterogeneidad mostrada (HM) está ligada a los procesos de representación de dicha constitución en la superficie enunciativa. Los dos niveles mantienen cierta simetría con oposiciones conocidas: el locutor sicoanalítico (1) frente al locutor narrador ( $\mathbf{L})$; la heterogeneidad que «constituye» un discurso en el sentido de cómo está hecho su tejido frente a la heterogeneidad mostrada que «constituye» un discurso en el sentido de cómo se relaciona con el exterior (op.cit:107).

I.2. En definitiva, ambas heterogeneidades son irreductibles pero articulables y necesariamente solidarias. No obstante, nuestro interés se centrará en la HM que se manifiestan explícitamente en el plano de la enunciación: distanciación, desdoblamiento o división del sujeto, marcas polifónicas o de interdiscurso, etc. Los puntos localizables de la HM se reconocen a través de algunas irregularidades gramaticales, variaciones formales del código, el discurso interrumpido y marcas tipográficas. Tales manifestaciones, en consecuencia, pueden ser de dos clases: marcadas y no marcadas. Las formas marcadas establecen el lugar del «otro» a través de una marca unívoca (ya sea ésta de carácter tipográfico o sintáctico), como en el caso de los términos y frases entrecomilladas o en cursiva, los incisos, el discurso directo e indirecto, las citas, etc. Las formas no marcadas, aunque no estén resaltadas, pues carecen de dicha marca unívoca, se reconocen por sus efectos polifónicos: discurso indirecto libre, ironía, referencias intertextuales, paráfrasis, pastiche, parododia, etc.

En el cuadro inferior, ofrecemos una relación de las estrategias de HM que examinaremos a continuación:

2 Entendemos como formación discursiva un haz complejo de relaciones que funcionan como regla, caracterizando las condiciones de aparición de un discurso en tanto práctica (Maldidier et al, 1972:128). 
FORMAS MARCADAS

- Discurso directo

- Glosas metadiscursivas

- Términos entrecomillados
FORMAS NO MARCADAS

- Discurso indirecto

— Disc. ind. libre

- Paráfrasis

- Ironía

- Cita de autoridad

- Proverbio

- Lemas y consignas

Las manifestaciones de HM, como las citas, los lemas, las consignas y los proverbios, pueden ser o no secuencias marcables, opción que en último término toma el hablante. Lo relevante de tales fenómenos enunciativos es su capacidad de introducir voces de otros enunciadores a través de la palabra del locutor $(\mathbf{L})$, actos polifónicos que dan lugar a estrategias interdiscursivas y metadiscursivas. Los cambios en los niveles de enunciación permiten el ocultamiento o aparición de $\mathbf{L}$ («embrayeur/débrayeur») ${ }^{3}$ o la «delegación» de la palabra de $\mathbf{L}$ a otros enunciadores no hablantes (la ironía, por ejemplo). En definitiva, tales mecanismos rompen o alteran la imagen de un mensaje monódico, revelando huellas de otros discursos y de sus enunciadores.

\section{LA POLIFONIA}

II.1. La heterogeneidad mostrada está relacionada directamente con los hechos polifónicos del discurso. La polifonía, tal y como la entiende Ducrot (1986), viene a ser un fenómeno de multivocidad: la expresión de una serie de enunciadores y de diferentes niveles de locutores en un mismo enunciado. Ducrot considera que el sujeto hablante sufre una escisión al convertirse en figura enunciativa. En consecuencia, tenemos un sujeto en tanto «ser de mundo» (sujeto físico, l) y un sujeto en tanto «ser del discurso» (locutor $\mathbf{L}$ ). El locutor $\mathbf{L}$ es una ficción discursiva que no coincide necesariamente con el productor físico del enunciado. La división del sujeto hablante en $\mathbf{L}$ y $\mathbf{l}$ es una de las manifestaciones de polifonía en el enunciado. Obsérvese, por ejemplo, que en los discursos autobiográficos, $\mathbf{L}$ habla de $\mathbf{I}$, mientras que, en la autocrítica, $\mathbf{L}$ humilla a $\mathbf{l}$. En ambos casos, el locutor $\mathbf{L}$ se toma a sí mismo como objeto de su enunciación, pero no en tanto orador, sino en tanto ser de mundo (op.cit:206).

3 Los «embragues» o «shifters» (Jakobson, 1975:178) son elementos lingüísticos deícticos que integran en el enunciado aspectos concretos del contexto de la comunicación, como los pronombres personales (1ra. y 2 da. persona del singular y plural), los adverbios temporales (hoy, en este momento, pasado, mañana, etc.) y espaciales (aquí, acá, etc.). 
II.2. Otra importante manifestación de la que nos habla Ducrot (op.cit:208) es la presencia de enunciadores $(\mathbf{E})$, «seres que se expresan a través de la enunciación, sin que por ello se les atribuya palabras precisas». Los enunciadores no hablan, pero la enunciación les permite exponer su punto de vista. La autoridad narrativa de $\mathbf{L}$ le permite introducir en su propio enunciado posiciones distintas a las suyas, sobre las que puede estar o no de acuerdo. Así, L presta su «voz» como canal a fin de que $\mathbf{E}$ pueda expresarse. La actitud de $\mathbf{L}$ es similar a la que establece el narrador de la obra literaria con sus personajes. Tradicionalmente, el conocimiento o información que posee el narrador $(\mathbf{N})$ de tercera persona sobre sus personajes (P) se determina en tres grados: suprasciente $(N>P)$, equisciente $(\mathrm{N}=\mathrm{P})$ o infrasciente $(\mathrm{N}<\mathrm{P})$ (Tacca,1978:72). En este sentido, es posible establecer que $\mathbf{L}$ se presenta como un narrador suprasciente $u$ omnisciente pues, aunque sea él quien habla, no es el centro de la perspectiva desde cuyo punto de vista se nos presentan los acontecimientos. De forma similar, los enunciadores no hablan en el sentido material del término, sino que lo hacen a través de $\mathbf{L}$, quien expresa el punto de vista, posición o actitud de $\mathbf{E}$ como sujeto de consciencia (Banfield, 1979). La actidud de $\mathbf{L}$ frente a $\mathbf{E}$ puede ser de alejamiento (la ironía) o de adhesión (la consigna). Los mecanismos que articulan la identificación o rechazo de la intrusión de $\mathbf{E}$ en el enunciado de $\mathbf{L}$ son precisamente las huellas de la heterogeneidad mostrada. De esta forma, $\mathbf{L}$ se siente en la obligación de separar su discurso de las palabras extrañas de $\mathbf{E}$, por medio de marcas tipográficas o códigos gramaticales, en ocasiones, sumamente sutiles y difíciles de distinguir.

Hemos de precisar que el locutor $\mathbf{L}$ también puede hacer referencias a su propio discurso y, en tal caso, su voz hace el papel del enunciador. La propiedad metadiscursiva permite a las lenguas naturales describirse a sí mismas sin pasar a otro sistema semiótico. Maingueneau (1987:66) señala que el metadiscurso permite que $\mathbf{L}$ construya distintos niveles en el interior de su propio discurso, posibilitando la asociación de los enunciados y sus comentarios en cualquier momento a través del discurso. Más adelante, nos detendremos en las glosas, mecanismos metadiscursivos que permiten reajustar, resaltar o rectificar la trayectoria de la enunciación de $\mathbf{L}$.

\section{EL DISCURSO REPRODUCIDO}

III.1. Con frecuencia, el problema del discurso reproducido, que abarca los discursos directo, indirecto e indirecto libre, es objeto de múltiples interpretaciones en relación con su naturaleza enunciativa. En realidad, todos los fenómenos polifónicos que analizaremos son discursos reproducidos en tanto que establecen una relación intertextual con discursos ajenos al de L. Sin embargo, las tres modalidades arriba señaladas conforman un cuadro particular en la medida en que intentan reproducir un acto de enunciación total. 
La oposición entre el discurso directo (DD) y discurso indirecto (DI), segun Authier (1978:47), se puede describir como la oposición de dos formas linguísticas que aparecen en un contexto introducidas por el elemento lexical decir (archilexema de los verbos de comunicación). De esta forma, se podría establecer que el DD (<decir:»...»>) es la manifestación de una operación de citación que transmite la forma y el significado de las palabras reproducidas; en tanto, el DI (<decir que ...>) señala una operación de paráfrasis que trasmite el sentido de las palabras reproducidas. No obstante, los problemas de interpretación surgen de inmediato.

III.2. Comúnmente, el DD se ha concebido como la reproducción «objetiva» y «textual» de una enunciación anterior. Pero en realidad no hacemos más que reproducir el enunciado y nunca la enunciación original. En el DD oral, $\mathbf{L}$ hace un esfuerzo por restituir el tono, la voz, el acento e, incluso, la mímica de $\mathbf{L}_{\mathbf{0}}$ (locutor de la enunciación del enunciado original o fuente de reproducción). Esta supuesta imitación intenta garantizar la reproducción exacta y fiel de la enunciación original. Aparentemente, $\mathbf{L}$ trata de mantener la distancia para no intervenir en el enunciado de $\mathbf{L}_{\mathbf{0}}$, pero ello no asegura la veracidad de la palabra reproducida. Es una falacia discursiva en la que $\mathbf{L}$ hace creer que reconstruye la situación de comunicación del mensaje reproducido:

«Un DD n'est pas simple juxtaposition de deux actes d'énonciation, ayant le même statut, celui de L-R, celui l-r. La chaîne rapportée entre guillemets qui, à un certain niveau, échappe au contrôle de L, n'a en fait d'existence linguistique qu'à travers le message de $L \gg$ (op.cit:52)

De esa misma manera piensa Ducrot (1986:204) cuando afirma: «Que el estilo directo implique hacer hablar a otro, hacerle asumir emisiones, no significa que su verdad resida en la correspondencia literal término a término». El DD consiste en una enunciación única que introduce dos locutores diferentes ( $\left(\mathbf{L}\right.$ y $\mathbf{L}_{\mathbf{0}}$ ), de manera similar al narrador que inserta en su relato a otro narrador secundario. En definitiva, el DD reproduce -cita- las palabras de otro, pero nunca llega a alcanzar la fidelidad de reproducción del acto de enunciación original.

III.3. Por su parte, el DI no pretende citar fielmente el enunciado original, sino «traducir» las palabras de $\mathbf{L}_{\mathbf{0}}$ como si de dos códigos se tratase pero en el campo del mismo sistema lingüístico. El subordinante que aparece como la marca de una operación de traducción que equivale a decodificar y recodificar nuevamente. En este sentido, $\mathbf{L}$ reutiliza las palabras de $\mathbf{L}_{0}$ para decir lo que éstas significan, o sea, realizando una paráfrasis a nivel de sentido. Pareciera ingenuo, por lo tanto, intentar establecer una relación de subordinación, reduciendo el DI a una variante «cuasi-textual» (Authier, op.cit:88) del DD: 
«(..) le DD cite les mots de I, alors que le DI traduit les mots de I; ni l'un ni l'autre, en soi,ne parle avec les mots d'un autre.»

III.4. Como anteriormente señalamos, las manifestaciones de $\mathbf{H M}$ proceden de un discurso anterior que $\mathbf{L}$ inserta en su enunciado, dejando huellas en él de voces ajenas y exteriores a su discurso. Aunque tales manifestaciones pueden proceder o bien de la citación (DD) o bien de la paráfrasis (DI), existen otras operaciones, como la ironía, que deben ser interpretadas como una interferencia entre ambas modalidades. El discurso indirecto libre (DIL) no es, como generalmente se considera, una simple forma intermedia entre el DI y el DD. Es otro proceso de reproducción, que Banfield (1979:9) denomina «palabra y pensamiento representados». El DIL autoriza las exclamaciones, las interrogaciones y otros elementos expresivos que no se presentan en el DI; por otra parte, admite la deixis espacio-temporal de $\mathbf{L}$ en el discurso que reproduce, hecho que en el DD no es posible. Lo verdaderamente característico del DIL es la representación del punto de vista de una tercera persona, el sujeto de consciencia (S). Teóricamente, en este tipo de discurso, $\mathbf{L}$ reproduce -traduce- el discurso de $\mathbf{L}_{\mathbf{0}}$. Pero lo reproducido no puede ser una manifestación de DI puesto que no hay paráfrasis ni traslación de significados. Existe una clara presencia de un enunciador que no habla puesto que siempre lo hace $\mathbf{L}$. El enunciador $\mathbf{E}$ o $\mathbf{S}_{\mathbf{c}}$ es el centro de la perspectiva desde la cual $\mathbf{L}$ desarrolla su enunciado. Al igual que el narrador omnisciente y testigo (Tacca, 1978:144), L habla por su personaje y está comprometido con él, imprimiendo las marcas de subjetividad de la palabra o pensamiento de $\mathbf{S}_{\mathbf{c}}$ en el enunciado reproductor.

\section{LA PARAFRASIS}

IV.1. La sinonimia de frases o paráfrasis es un proceso de reformulación por medio del cual se restituye el sentido de un discurso ya producido. Anteriormente señalamos que el DI involucra un mecanismo parafrástico en el momento de «traducir» el sentido de un enunciado original al enunciado reproductor. Por ello, la paráfrasis, en tanto reformulación intralinguiística, se asemeja a la «traducción» interlingüística del DI. Sin embargo, la paráfrasis identifica dos términos diferentes ( $\mathbf{X}$ e $\mathbf{Y}$ ) en un mismo discurso y, en consecuencia, se convierte en una meta-predicación de identificación (Fuchs,1982:31). Para esta autora, la paráfrasis se define como una actividad metalinguística de identificación entre los semantismos de $\mathbf{X}$ e $\mathbf{Y}$.

No obstante, decir «de manera diferente» la misma cosa no constituye una condición suficiente de sinonimia, puesto que la reformulación parafrástica puede desplazar el sentido de $\mathbf{X}$ y hacerlo equivaler al de $\mathbf{Y}$ sin que dicha equidad 
esté constituida en el interior del sistema lingüístico, como sí ocurre en las sinonimias. La reformulación de un constituyente en otro se logra a través de marcas de identificación (op.cit:31) del tipo «es decir», «dicho en otras palabras», etc. Estas marcas se presentan como la identificación de los semantismos respectivos de la expresión reformulada $\mathbf{X}$ y la expresión reformulante $\mathbf{Y}$. Es posible hacer toda una tipología de paráfrasis considerando no sólo los elementos de la reformulación, sino también la situación y el sujeto parafraseador.

Las marcas de identificación son muy numerosas aunque sintácticamente podríamos considerarlas formas de coordinación, no sólo frásicas («o sea», «dicho en otras palabras»), sino también unidades morfemáticas («0», «como»). También verbos de carácter copulativo (ser, constituir, significar, etc) sirven para reformular un término en otro. Tales marcas funcionan con base en la connotación «autonymique», ${ }^{4}$ que marca cierta distancia o separación entre el constituyente $X$ y $Y$, sin que se dé una ruptura sintáctica en el hilo discursivo. El mencionado distanciamiento puede autorizar a $\mathbf{L}$ a cambiar los signos del código. En efecto, la paráfrasis no es discursivamente neutra; en apariencia, se muestra como una tentativa para controlar, en los puntos neurálgicos, la polisemia abierta por la lengua y el interdiscurso (Maingueneau, 1987:69). Sin embargo, antes de reconstituir una equivalencia preexistente, la paráfrasis puede crear la ilusión de una identidad que no es tal y que $\mathbf{L}$ pretende hacer creer al destinatario para sus propios fines. El discurso político, por ejemplo, recurre con frecuencia a esta estrategia discursiva, en la medida en que el sujeto político, por su capacidad modal de hacer-creer, establece la equivalencia de dos términos, equidad que éste, desde su posición de poder y saber (hacer), garantiza sin problemas.

\section{EL METADISCURSO: las glosas}

V.1. Además del comportamiento meta-lingüístico de la paráfrasis, existen otras manifestaciones, en este caso, metadiscursivas que permiten asociar términos diferentes bajo un código común: el utilizado por $\mathbf{L}$. Las marcas metadiscursivas dejan en evidencia la consciencia de $\mathbf{L}$ sobre su propio discurso y su capacidad para ajustarlo continuamente a la situación comunicativa, comentando sus palabras con sus mismas palabras. El metadiscurso es un juego en el interior del discurso de tal forma que $\mathbf{L}$ finalmente puede adueñarse de su capacidad discursiva. Hay una gran diversidad de operadores funcionales que denominamos glosas (Authier,1984:105) y que permiten la corrección, rectificación o exaltación del discurso de $\mathbf{L}$. Es importante señalar que muchas glosas funcionan como marcas de identidad entre $\mathbf{X}$ e $\mathbf{Y}$ debido, precisamente, a la capacidad

\footnotetext{
4 Término de Josette Rey-Debove citado por Authier (1978: 69).
} 
meta-lingüística del proceso parafrástico. A continuación, haremos un recuento de algunas glosas en función metadiscursiva:

a) Adecuación: L construye su imagen de locutor adecuándose a las palabras de otro locutor:

$$
\text { «como hablan los políticos,...» }
$$

b) Modal de enunciado: Aunque se asemeja mucho a la glosa de adecuación, en ésta $\mathbf{L}$ hace referencia a la modalidad del enunciado y no a las características locutor: «metafóricamente hablando,...» «claramente hablando»

c) Modal de enunciación: A través de esta glosa, $\mathbf{L}$ interviene y evidencia el carácter de su enunciación:

$$
\begin{aligned}
& \text { «francamente hablando...» } \\
& \text { «hablando con sinceridad...» }
\end{aligned}
$$

d) Rectificación: $\mathbf{L}$ sustituye el término $\mathbf{X}$ por $\mathbf{Y}$ manifestando que es un hecho de autocorrección. Este tipo de glosa posee un marcado carácter parafrástico: «X, o mejor dicho, $\mathbf{Y} »$ «Más bien que...»

e) Especificación: $\mathbf{L}$ amplía el sentido del término $\mathbf{X}$ gracias a un inciso que especifica, aclara o determina el significado que se le quiere dar.

$$
\begin{aligned}
& \text { «..en el sentido literal del término» } \\
& \text { «..en la acepción original de la palabra» }
\end{aligned}
$$

f) Permisión: L solicita el beneplácito, en un acto conativo, al interlocutor para emplear ciertos términos:

$$
\begin{aligned}
& \text { «Si se me permite la expresión...» } \\
& \text { «...o si ustedes lo prefieren...» }
\end{aligned}
$$

g) Predicción: L hace una predicción sobre un término $X$ antes de enunciarlo, para negarlo y quizás después rectificarlo: «Yo no diría que..X..mas bien que...Y»

h) Anaforización: L vuelve sobre algún enunciado anterior por medio de ciertas frases conectoras de anaforización y también deícticas. Estas glosas se encuentran con mayor frecuencia en el discurso escrito.

«En el caso del que hablamos...»

«Como veníamos diciendo...» 
i) Enfática: algunas glosas anafóricas, además, hacen énfasis en enunciado anterior y no sólo referencia.

«Vuelvo a repetir...»

«Quiero volver a insistir en...»

Estas dos últimas glosas son especialmente importantes en la organización del argumento del discurso. Con frecuencia se les denomina conectores argumentativos (Maingueneau,1990:53), aunque su análisis lingüístico ha sido tradicionalmente ignorado. Sin embargo, el valor de los conectores consiste en poder unir dos unidades semáticas, generalmente, dos enunciados, pero también otras entidades heterogéneas: un enunciado y una enunciación, un hecho extralingüístico y un enunciado, un elemento explícito y otro explícito, etc. El resultado de dicha relación se manifiesta en el papel argumentativo que adquieren esas unidades léxicas, lo que produce la coherencia final del discurso.

\section{LA IRONIA}

VI.1. Según Ducrot (1986:214), la ironía tradicionalmente se define como una antífrasis: «se dice $A$ para dar a entender no $A$, entendiéndose que el responsable de A y no A son idénticos». Sin embargo, la ironía es una de las formas más interesantes de HM, ya que no siempre porta marcas explícitas en el enunciado y, no obstante, es una estrategia de doble enunciación. Otras manifestaciones polifónicas (los ecos, los diálogos internos, el eclipsamiento del portavoz ante la persona a la que hace hablar, etc.) también permiten la presencia de enunciadores. No obstante, la ironía posee la particularidad de que $\mathbf{L}$ introduce en escena a un $\mathbf{E}$ que adopta una posición absurda, sobre la cual $\mathbf{L}$ no está de acuerdo. De esta forma, $L$ hace decir cosas «fuera de lugar» a un E, o sea, hace oír una voz -que no es la suya-y que sostiene lo insotenible:

«Hablar de manera irónica equivale para un $\mathbf{L}$, a presentar la enunciación como si expresara la posición de un $\mathbf{E}$, posición que $\mathbf{L}$ no se responsabiliza y que considera absurda». (op.cit:215)

La ironía, pues, es un fenómeno sutil y nada ingenuo, que busca la ambigüedad del mensaje producido. Además, debe verse, en la función irónica, un gesto hacia el destinatario y no una actividad lúdica y desinteresada; por el contrario, manifiesta una actitud agresiva o defensora de parte de $\mathbf{L}$. Como observa Maingeneau (1987:71), el interés de la estrategia de la ironía consiste en autorizar a $\mathbf{L}$ a subvertir las fronteras de la coherencia de la argumentación, puesto que produce un enunciado que posee simultáneamente dos valores contradictorios sin que por ello se someta a las sanciones que la incoherencia entraña. 
VI.2. En apartados anteriores, hemos establecido una equivalencia entre el DIL tipificado en el narrador omnisciente de tercera persona y la ironía. Efectivamente, las muestras de un sujeto de consciencia que «ve» por medio de las palabras de $\mathbf{L}$ en ambos casos es idéntica. Sin embargo, para que un enunciado sea irónico, $\mathbf{L}$ no debe homologarse a $\mathbf{E}$, origen del punto de vista expresado. Es esencial, por lo tanto, que $\mathbf{L}$ no se identifique (asuma, apoye o responsabilice) con la perspectiva de $\mathbf{E}$; a la inversa, siempre ha de mantener la distancia que garantice la autonomía de ambas voces. En consecuencia, la ironía puede recurrir a formas marcadas tipográficamente - comillas, cursiva, puntos suspensivos, etc.- - para evidenciar tal separación ${ }^{5}$. Son frecuentes también sintagmas modalizantes del tipo «desde luego», «evidentemente», «por supuesto», que, en un contexto adecuado, resaltan la contradicción de $\mathbf{L}^{6}$. En el discurso oral, son los índices paraverbales los que delimitan la separación (entonación, gestos, etc.), aunque en la escritura podemos recurrir a glosas modales de enunciación («dicho irónicamente»). Pero, sin duda, la ironía más sutil es aquella que se desarrolla en el marco contextual carente de cualquier marca explícita en el enunciado?

\section{LA CITACION: La cita de autoridad, el proverbio y el lema}

VII.1. La citación es la marca que evidencia el discurso directo por excelencia. Como hemos apuntado, en el DD, $L$ reproduce un enunciado anterior pero nunca su enunciación. De esta forma, $\mathbf{L}$ intenta legitimar el enunciado reproduciéndolo en un afán y búsqueda de realidad u objetividad. El acto de citar consiste en «extraer un material que ya tiene su significado en un discurso para hacerlo funcionar en un nuevo sistema de significación» (Maingueneau, 1980:141). No cabe duda, sin embargo, que la cita pretende separar deliberadamente el discurso reproductor del reproducido, aumentando la distancia mediante marcas no sólo tipográficas (comillas, dos puntos, etc.), sino también, en muchos casos, identificando la fuente de origen del discurso reproducido ( «según X:...»; «tal y como apunta $X: . . . »$, etc.). Los verbos de comunicación ${ }^{8}$ son fundamentales para definir la posición de $\mathbf{L}$ frente a la cita. Charolles (1976:93) considera tres tipos de verbos de comunicación: a) los neutros, como decir, articular, declarar, ex-

${ }^{5}$ Ej: «Recordemos que tanto halcones como palomas consideran la ayuda a la Contra partiendo de la base de que su propósito principal es el «noble objetivo» de «democratizar Nicaragua» (Chomsky: 1989).

${ }^{6}$ Ej: «El símbolo del Partido Republicano, desde luego, ha sido siempre un elefante. Resulta desonsolador verlo comportarse como tal delante de una polilla» (Chomsky: 1989).

${ }^{7}$ Como, por ejemplo, la manifestación de un rasgo hiperbólico en el enunciado que ridiculice el punto de vista de $\mathbf{E}$.

8 Según este autor, la estructura profunda de los verbos de comunicación sería la siguiente:

$\begin{array}{lccc}\text { VCOM } & \mathbf{X}_{1} & \mathbf{X}_{2} & \mathbf{X} \\ \text { (digo) } & \text { (agente) } & \text { (dativo) } & \text { (objeto) }\end{array}$


presar, etc., puesto que no permiten realizar presuposiciones, es decir, no remiten a la relación de $\mathrm{x}_{1} \circ \mathrm{x}_{2}$ con $\mathrm{x}$; $\mathbf{b}$ ) los presuposicionales, como contestar, replicar, divulgar, objetar, pues remiten a la aparición temporal de la comunicación y a la naturaleza de $\mathrm{x}_{1} \mathrm{y}_{2}$ (contextualidad); y c) los modales que se subdividen en pragmáticos y performativos. Los primeros (murmurar, cuchichear, aullar, etc.) indican una relación de x 1 con el objeto x. Los performativos, - si bien la performatividad parece ser un empleo más que un rasgo semántico inherente, según este autor (op,cit:98) - implican una relación de $\mathrm{x}_{1}$ a $\mathrm{x}_{2}$ a propósito de $\mathrm{x}$ : ordenar, notificar, jurar, prometer, etc. Es posible, entonces, relacionar los verbos de comunicación que introducen una cita con el grado de adhesión de $\mathbf{L}$ y el elemento reproducido.

VII.2. Por otra parte, la identificación de la fuente de origen nos permite establecer, al menos, tres clases de citaciones en las que varía la relación de $\mathbf{L}$ con $\mathbf{L}_{\mathbf{0}}$. Veamos:

CITA DE AUTORIDAD: corresponde a la cita clásica en la que $\mathbf{L}$ se eclipsa ante un locutor $\mathbf{L}_{0}$ que profiere un enunciado del cual no se hace responsable. Es el caso típico del DD. En este tipo de cita, $\mathbf{L}$ se siente en la obligación de revelar la fuente de origen: la adhesión de $\mathbf{L}$ hacia la cita reproducida puede ser total («como dice acertadamente $X: » \ldots »)$; neutra (como dice $X: » . . »)$; o nula («..en contra de lo que dice $X: » . . . »)$. No debemos olvidar, sin embargo, que los matices de adhesión pueden ser difíciles de detectar fuera del contex to comunicativo.

La cita de autoridad tiene, como condición, el poder ser reconocida por gran parte de la colectividad de hablantes. A veces, no se necesita nombrar necesariamente la fuente de origen, puesto que el nombre del creador-ausente es por todos conocido. El mensaje de $\mathbf{L}$ reposa, pues, sobre un sistema de referencias común entre éste y su receptor. Muchas de estas citas-reliquia (Maingueneau,1980:142) son literarias, bíblicas o históricas ${ }^{9}$ y pueden llegar a estar tan extendidas que adquieren un uso proverbial -aunque no deben ser confundidas con el proverbio como veremos más adelante-. Otras modalidades de citas de autoridad son la cita-prueba y la cita-epígrafe. La primera ayuda a refutar o defender una argumentación en un discurso dado; casi con obligatoriedad, la fuente de origen debe ser explícita. La cita-epígrafe liga un nuevo discurso con un conjunto textual más amplio a fin de identificarlo con un grupo definido de formaciones discursivas anteriores.

" Ej: Literaria: «En un lugar de la Mancha...».

Bíblica: «Perdónalos, Padre, pues no saben lo que hacen».

Histórica: «Vini, vidi, vinci». 
EL PROVERBIO: Comparte características idénticas con la cita-reliquia, en la medida en que son parte del diccionario cultural de la lengua, verdades inmemoriales que conoce la colectividad. Sin embargo, la fuente de origen es absolutamente desconocida, anónima y, ante todo, no es preciso reestablecerla. Todos los hablantes pueden hacer uso de proverbios, pues a todos nos pertenecen; sin embargo, la cita-reliquia tiene un carácter mucho más restringido.

Como un eco, el proverbio es la repetición de un número ilimitado de enunciados anteriores. El locutor que cita un proverbio hace uso de él, generalmente, para solidarizarse con el mensaje del enunciado. No debemos olvidar que muchos proverbios tienen un carácter didáctico y moralizante, lo que justifica la adhesión de $\mathbf{L}$ con el discurso reproducido.

EL LEMA: Al igual que el proverbio, en el lema o eslogan (publicitario y político preferentemente) hay una ausencia total de referencia a la fuente de origen. Sin embargo, pareciera que su enunciación va dirigida a cada uno de los receptores de una comunidad de hablantes, creando la ilusión de que uno es el receptor particular de dicho enunciado. Este efecto se encuentra muy extendido en las campañas electorales y en los anuncios publicitarios. Los aspectos enunciativos en la propaganda comercial y política son muy ricos aunque complejos, debido a la heterogeneidad de formas permisibles y a la constante creación de manifestaciones que buscan un impacto afectivo e ideológico en el receptor.

El lema se caracteriza por estar ligado a una práctica específica, pues induce a la ejecución de un acto intelectual y luego físico (considerando que una «decisión» puede ser un acto intelectual previo a la acción física). Por ello, creemos que el lema, sin tener una fuente conocida, tiene una fuente «reconocida», compuesta por todos y cada uno de los emisores/receptores en masa que se adhieren a su mensaje. El lema político, por ejemplo, no suele ser adjudicado a un $\mathbf{L}$ físico concreto - al menos en la mayoría de los casos-. Sin embargo, los receptores que captan el mensaje y que cumplen el proceso total de decodificación, sabrán muy probablemente de dónde procede ese mensaje (un partido político, un movimiento, etc.). El lema, en contraposición al proverbio, espera ser reconocido como producto de una fuerza supraenunciadora instalada por encima de los sujetos concretos de la comunicación. Su procedencia debe ser localizada e identificada para no caer justamente en el anonimato del proverbio. El hablante que pronuncia y repite un lema lo asume de tal forma que se convierte 'ipso facto' en su sujeto de enunciación, aunque no sea su creador original. Debemos tener presente que el sujeto de la enunciación, en última instancia, es aquel que se responsabiliza, asume y solidariza con su enunciado. El caso del eslogan político parece ser una manifestación no sólo de máxima adhesión, sino de entera apropiación.

A continuación, presentamos un cuadro comparativo con cuatro variables que permiten distinguir los rasgos de los tres tipos de citación analizados: 
CITA DE AUTORIDAD:

(«Vini, vidi, vinci»)

\section{PROVERIO:}

\section{(«Todo buchón muere pelón»)}

\section{LEMA:}

\section{(«iPatria libre o morir!»)}

(+PROCEDENCIA): Identifica o reconoce el espacio enunciativo de donde procede el enunciado reproducido. La cita definida como literaria, histórica, periodística o científica, alude al universo discursivo de dónde procede. Del mismo modo, es posible determinar el lema comunista, fascista, revolucionario, etc., así como la publicidad de tabaco, de automóviles, gubernamental, entre otras. El proverbio parece tener un universo discursivo ilimitado, el cual se genera en todas las instancias $y$, a la vez, no pertenece a ninguna en particular.

$\left(+\mathrm{L}^{0}\right)$ : El locutor del enunciado original suele ser explícito únicamente en la cita de autoridad. En los dos casos restantes, dicho sujeto es desconocido o de importancia secundaria. El rasgo (-) no equivale a la inexistencia de $\mathbf{L}_{0}$ sino a su anonimato.

$(+<=>)$ : Este signo establece la adhesión en términos generales entre $\mathbf{L}$ y la cita reproducida. En el lema y en el proverbio existe una tendencia a la «apropiación» del mensaje, mientras que en la cita se dan grados de mayor o menor «solidarización» con las palabras citadas.

: $\quad(+\mathrm{L})$ : Siempre es posible localizar al locutor de la enunciación reproductora en la medida que reproduce un enunciado ajeno. Aquello que no forma parte del enunciado reproducido es, por defecto, parte de la enunciación de $\mathbf{L}$

\section{LAS COMILLAS}

VIII.1. Las comillas, como otras marcas tipográficas -cursiva, negrita, etc.--, establecen una separación entre el discurso y la frase entrecomillada. Unicamente en el caso del DD, tal separación causa una ruptura sintáctica, por medio de la cual, el enunciador «menciona» las palabras del otro, en un acto de citación en su sentido más estricto (Authier,1984:103). No obstante, es frecuente que, en las 
frases o términos entrecomillados, no se produzca dicha ruptura, sino un fenómeno de «connotation autonymique», en el que el fragmento entrecomillado sea, al mismo tiempo, «mencionado y «utilizado». En otras palabras, la voz o palabra «del otro» está integrada en el discurso sin incurrir en ruptura sintáctica alguna; se encuentra inscrita en la continuidad sintáctica del discurso del sujeto enunciador. Los sintagmas entrecomillados proceden de otra dimensión enunciativa que $\mathbf{L}$ marca para no asumir la entera responsabilidad, no tanto de su significación como de su connotación (todo lo que conlleva un significado sin formar parte explícitamente de éste):

«Las comillas constituyen en cierta forma el emblema de flexibilidad y de la complejidad de los mecanismos de cita: ora un deslizamiento del enunciador se efectúa subrepticiamente en su ausencia, ora su presencia señala algo distinto que un verdadero cambio de locutor» (Kerbrat-Orecchioni, 1986:215)

Siguiendo algunas descripciones de J.Authier sobre las funciones demarcativas de las comillas (en Maingueneu,1987:64), hemos elaborado un listado con sus usos más frecuentes:

a) Distinción: $L$ trata de establecer una distinción para mostrar que el término entrecomillado pertenece al exterior de su discurso y cuya responsabilidad no asume. En realidad, esta función siempre prevalece frente a las demás:

«Bush rechaza por «inaceptable» la oferta de paz de Sadam Husein» (El Independiente, 16-2-91)

«El Ministro del Interior «desea» que el juicio contra Amedo y Domínguez se celebre cuanto antes» (El Pais, 14-2-91)

b) Pedagógica: Se trata de una función de distinción pero en relación con la vulgarización de un término que pertenece a otro registro socio-linguístico:

«Los «nicas» somos gente alegre. A la insurrección le llamamos popularmente «la runga», y a este proceso electoral, la «gran fiesta»» (El Independiente, 4-3-90)

c) De protección: señala que el uso de las palabras utilizadas no es más que aproximativo.

«Pero esta «guerra» no sólo afecta a la Iglesia Católica (de El Salvador)» (El País, 12-12-89)

d) De condescendencia: se acerca al uso irónico de las comillas, puesto que $\mathbf{L}$ accede a la utilización de un término que evidentemente no le pertenece. Es una especie de concesión que hace a $\mathbf{E}$ al utilizar su mismo lenguaje: 
«..., de los cadáveres calcinados y ennegrecidos de unas pobres «víctimas colaterales(...)» (El Independiente, 16-2-91)

e) Extranjerismos: marca términos tomados directa o indirectamente de otra lengua. Sin embargo, su uso no es meramente distanciador en relación con el código utilizado. Generalmente, puede connotar otras significaciones en determinado marco contextual, informando sobre una disposición más o menos favorable de $\mathbf{L}$ hacia la lengua escogida a fin de dar una imagen sobre su sustrato cultural, intelectual, mundano, etc.

«(...), concentrada en exclusiva en los exquisitos productos de «duty free» que estaban a su alcance (...)» (El País, 23 de febrero de 1991)

f) Neologismos: ante la extensión de un término nuevo sobre el que aún no hay consenso entre los usuarios e instituciones oficiales, $\mathbf{L}$ se previene antes de cometer algún" «abuso de uso» para demostrar que dicho término no pertenece a su registro habitual:

«Reagan, el primer «contra»» (El País, 22-4-90)

Finalmente, debemos tener en cuenta que la variedad de marcas tipográficas de las imprentas actuales permite distribuir las funciones de demarcación de diversas maneras. Por ejemplo, las comillas están reservadas para el DD o para una especie de discurso híbrido entre el DD y el DI que han creado estos medios de comunicación ${ }^{10}$. La letra cursiva o itálica suele emplearse según las funciones descritas arriba; en cambio, en las publicaciones y revistas semanales, se suele utilizar la «negrita» para resaltar los nombres de los personajes del artículo. Sin embargo, hay que advertir que estas opciones son muy variables y dependen, en gran medida, de la tecnología de que dispongan las empresas y del estilo impuesto por su redacción.

${ }^{10}$ Ej: A su juicio, «el comportamiento de la coalición ha sido correcto» y no se ha desviado de la ONU, mientras que Sadam dispara misiles sin seleccionar los objetivos y «tenemos la convicción de que utiliza escudos humanos» (El Independiente, 16-2-91). 


\section{BIBLIOGRAFIA}

AUTHIER-REVUZ, Jacqueline (1978), «Hetérogénéite(s) énonciative(s)». Languange, 73, pp. 98-111.

AUTHIER-REVUZ, Jacqueline y MEUNIER, André (1978), «Le discours rapporté», DRLAV, 17, pp. 47-85.

BANFIEL, Ann (1973), «Narrative Style and the grammar of direct and indirect speech». Foundations of Languages, 10 pp. 1-39.

BENVENISTE, Emile (1970). L'appareil formal de l'ennonciation». Langages, 17 .

CHAROLLES, Michelle (1976). «Exercises sur les verbes de comunication». Practiques, 9. pp. 83-98

DUCROT, Osawald. (1986) El decir y lo dicho. Barcelona, Paidós Comunicación.

FUCHS, Catherine (1982). «La paraphrase entre la langue et le discourse». Langue Francais, 13 , pp. $22-33$

GENETTE, Gérarad. (1979). Introduction à l'architexte. Paris, Seuil.

JAKOBSON, Roman (1975). Ensayos de Lingüística General. Barcelona, Seix Barral.

KERBRAT-ORECCHIONI, Catherine (1986). Laenunciación. Buenos Aires, Hachette.

MAINGUENEAU, Dominique (1980). Introducción a los métodos de análisis del discurso. Buenos Aires, Hachette.

- (1987). Nouvelles tendences en analyse du discourse. Paris, Hachette.

- (1990) Pragmatique pour le discourse littéraire. Paris, Bordas.

MALDIDIER, Denise; NORMAND, Claudine y ROBIN, Régine (1972). «Discourse et ideologie; quelque bases pour une recherche». Langue Francais, 15, pp. 117-141.

TACCA, Oscar (1978), Las voces de la novela, Madrid, Gredos. 